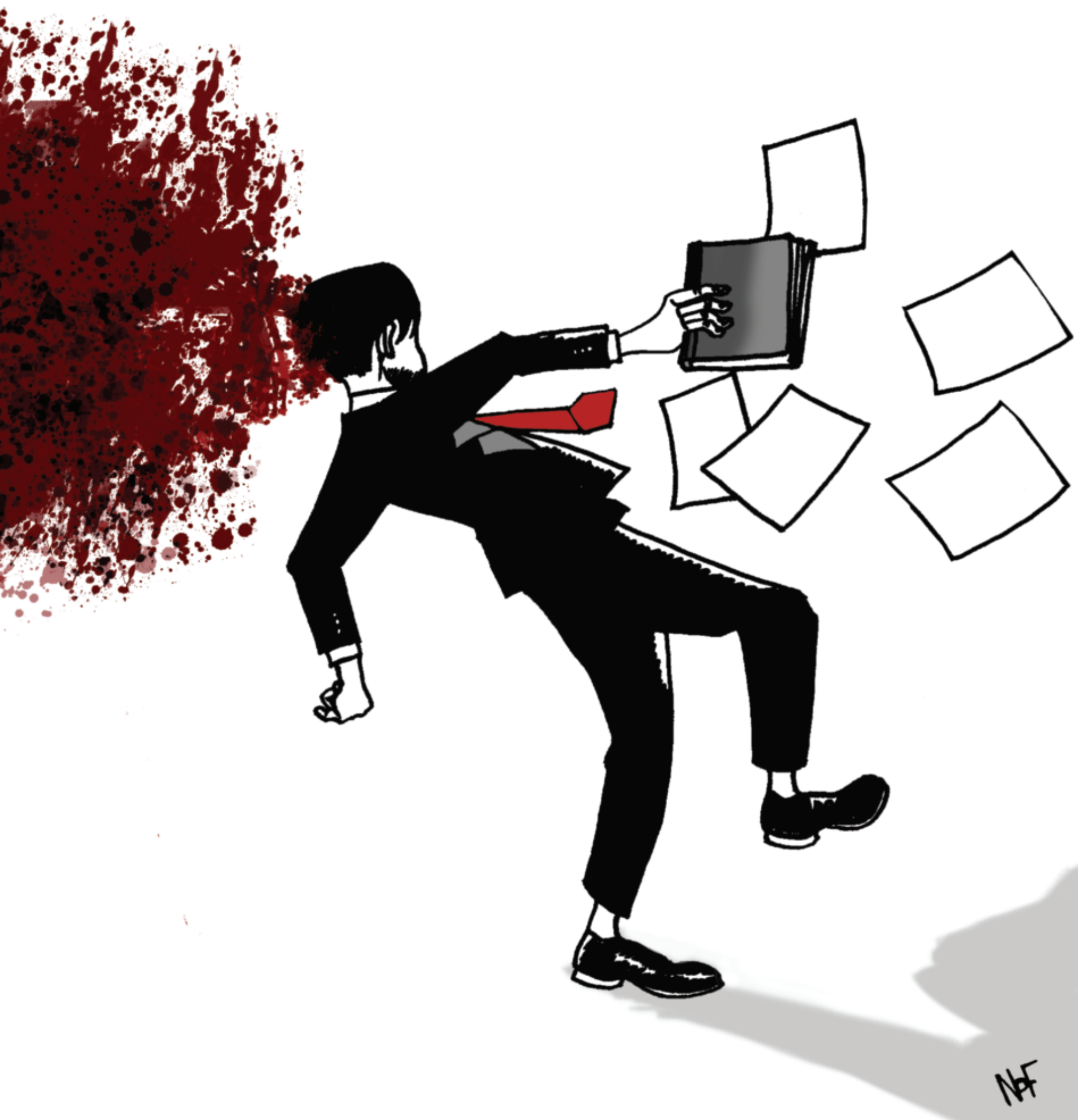




\section{Hacia una universidad}

\section{soberana de}

excelencia y crítica

\section{Los principios y caminos de su responsabilidad}

\section{Jaime Breilh**}

\section{Bases históricas y contexto}

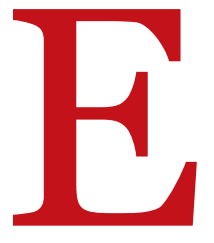

l papel de la universidad y su relación con el poder se ha transformado históricamente en nuestro país como producto de las cambiantes condiciones materiales y culturales de cada época, y de los paradigmas sobre el conocimiento que se impusieron.

Durante los siglos XVI y XVII el dominio absolutista y teocrático requirió de la escolástica como paradigma de un conocimiento impositivo que funcionalizó el control eclesiástico sobre los espacios universitarios.

* Basado en texto de conferencia dictada en el Paraninfo de la Facultad de Ciencias Médicas de la Universidad de Cuenca durante Exposición de proyectos de investigación; 13 de abril del 2011. ** Jaime Breilh, Md. PhD, Médico por la Universidad Central del Ecuador; Máster en Ciencias y Medicina Social por la Universidad Autónoma Metropolitana de México; posgrado en Epidemiología y Estadística, Escuela de Higiene y Salud Pública por la University of London; PhD en Epidemiología por la Universidade Federal da Bahia, Salvador de Bahía. Es Director del Área de Salud de la Universidad Andina Simón Bolívar, Sede Ecuador, profesor honorario de la Universidad de Cuenca; fundador y Director Ejecutivo del Centro de Estudios y Asesoría en Salud (CEAS); Presidente de la Comisión de Investigación del Sistema Nacional de Investigación Agraria (SIPAE). Entre sus publicaciones constan: El Sistema de Aspersiones Aéreas del Plan Colombia y sus Impactos sobre el Ecosistema y la Salud en la Frontera Ecuatoriana (Quito, 2007); Nuevo Modelo de Acumulación y Agroindustria: Las Implicaciones Ecológicas y Epidemiológicas de la Floricultura en Ecuador (Río de Janeiro, 2007); Aceleración Global, Agrocombustibles y Calentamiento Social en "Hacia una Agenda para las Economías Campesinas" (Quito, 2007), entre otras. 
3 Paladines Carlos. Pensamiento pedagógico ecuatoriano. Quito; Ediciones del Banco Central, 1988, p.24 4 Carlos Paladines, La ciencia y la educación ecuatorianas: Eugenio Espejo, González Suarez, Mutis y Humbolt, Quito, manuscrito, 1999. $5 \mathrm{Cfr}$. Fernando Tinajero, "Descubrimientos y evasiones...", op. cit., p. 242 6 Ibid., pp. 49-50

7 Darcy Ribeiro. A universidade necessária, São Paulo, Edição brasileira ( $1^{\circ}$ a $4^{\circ}$ ): Editora P\&T, 1969/1985

8 Aníbal Ponce. Educación y lucha de clases. México: Editores Mexicanos Unidos S.A. (2da edición) , 1978 9 Pablo Freire. Pedagogía del oprimido. Montevideo, Tierra Nueva, 1970 10 Jaime Breilh. Posmodernismo pensamiento liberador: una visión desde los sin poder. Quito: Revista Espacios, 9: 123-142, 1999
Ya para 1736 comenzó a declinar su peso, con la entrada del humanismo ilustrado y la presencia de la Misión Geodésica Francesa.

En la segunda mitad del Siglo XVIII, con los vientos independentistas y el avance de una conciencia emancipadora, irrumpe el paradigma de la Ilustración. La figura emblemática de ese movimiento fue Espejo quien acogió el problema de la transformación pedagógica y de la educación como terreno para la siembra. Proceso que culminó en el nuevo Plan de Estudios de la Universidad de Santo Tomás (1791) e impulsó una doctrina educativa ligada a la visión de un sector social en ascenso “...mestizos y artesanos incorporados a la plebe

urbana...(y)...abogados y grupos medios 'señores de la intelectualidad'...en lucha contra la sumersión social, política y educativa a que les había postergado el sistema colonial". ${ }^{3}$

En el Siglo XIX la perspectiva romántica que acompañó a la burguesía en la construcción de una sociedad de libertades individuales, cuestionó el pensamiento Ilustrado, volvió la mirada hacia la "cuestión nacional” y denunció los extremos sociales ${ }^{4}$. Hacia finales de dicho siglo un liberalismo transformado irrumpió en crítica al romanticismo filosófico y sustentó como salida el paradigma positivista. ${ }^{5}$

La movilización contra un liberalismo decadente y el intento por desmantelar el poder oligárquico terrateniente derivó en la Revolución Juliana, empujando un Estado de derechos sociales. La Junta de Gobierno Provisional reorganizó entonces la educación pública, buscó renovar las universidades, fomentó la instrucción técnica y científica en el país y decretó la autonomía universitaria. ${ }^{6}$ Eran los años en que las universidades de Sur América vibraban con los ecos del movimiento de la Federación de Estudiantes de Córdova en 1918. Ya en los años 70 los países dependientes de América Latina vivieron horas de agitación social intensa, que emplazaron también a las universidades y determinaron la retoma de los principios de la reforma universitaria de Córdova (autonomía universitaria; cogobierno; extensión universitaria; acceso por concurso a las cátedras; libertad de cátedra; masificación y unidad obrero-estudiantil; vinculación de docencia e investigación y del estudio con el trabajo; solidaridad latinoamericana e internacional). La llamada Segunda Reforma Universitaria buscó aplicar dichos principios y fue la expresión ecuatoriana de una transformación democrática profunda de las universidades inspirada en los ensayos de pensadores de distintas concepciones de la pedagogía latinoamericana como Darcy Ribeiro ${ }^{7}$, Aníbal Ponce $^{8}$ y Pablo Freire ${ }^{9}$.

Hacia fines del siglo XX, las universidades públicas ecuatorianas experimentaron una prolongada agonía del espíritu y el declive de la reforma. En el caso del Ecuador desde los 90 comenzó a incidir, aunque tardíamente, el movimiento de contrarreforma que acompañó en la educación al neoliberalismo estructural, imbuyendo un espíritu pragmático funcional y cuestionando las utopías sociales. El ojo del huracán de la cruzada neoconservadora fue la maximización del individualismo y la crítica a toda visión de totalidad. Los llamados posestructuralistas franceses emprendieron una agresiva cruzada para desacreditar lo que llamaron los métodos totalizantes y universalizantes, sembrar la incredulidad sobre toda interpretación social o colectiva de los fenómenos y proclamar que toda interpretación totalizante era parte de un poder opresor..$^{10}$

Los aparatos de propaganda intelectual se encargaron de llenar las librerías, los artículos de revistas y las notas periodísticas de esa filosofía y de una lógica que se proclamaron como posmodernas y que, a nombre de una crítica a la modernidad, introdujeron un profundo retroceso en los 
internacionales de dudosa calidad, que han crecido exponencialmente la matrícula, sobretodo de maestrías, sin un desarrollo paralelo de los sistemas de evaluación y certificación.

Las contradicciones y ambigüedades de la actual Ley Orgánica de Educación Superior son un terreno fértil para el avance de un modelo tecnocrático que en definitiva contribuirá a consolidar la línea funcionalista, pero ahora con mayor rigor y coherencia que en los años evidentemente neoliberales. La Ley implica más allá de los subterfugios jurídicos, un control directo del Ejecutivo sobre el Consejo de Universidades y los organismos de evaluación y certificación de la educación superior. Por otro lado, la actual política fomenta una peligrosa y no planificada presión a las universidades para el llenado rápido de las carencias de doctores y maestros, mediante mecanismos contradictorios a la retórica oficial de un desarrollo nacionalista y soberano, como son: la asignación preeminente de recursos para el crédito educativo para maestrías y doctorados en el exterior; la apertura a cuadros jubilados extranjeros formados en lógicas externas -operación Prometeo-; y la sorprendente ausencia de una política de prioridad y respaldo para programas doctorales nacionales de excelencia.

La confusión que en el campo de la educación superior se está produciendo entre lo que es el positivo principio de conducción público social de la educación superior, fortalecimiento de la universidad pública y control sobre las universidades comercializadas, con el ejercicio vertical y tecnocrático de una normativa funcionalista, traiciona el contenido y el espíritu de la

Constitución. Generando de esa manera procesos que condenan u obstaculizan el impulso de una formación de posgrado autónoma, de pensamiento crítico y centrada en las políticas de equidad y sustentabilidad social.

En los momentos actuales, y más allá de la retórica, existe la necesidad urgente de esclarecer el horizonte de la educación superior, y someter a un severo e informado escrutinio crítico a la nueva Ley y al marco institucional de gobierno universitario que se ha creado.

Un tema clave es analizar con objetividad la relación entre el Estado, la universidad y la colectividad. Se ha creado una gran confusión al respecto, como producto de algunas ambigüedades interpretativas y sobre todo por confusiones conceptuales como las que existen entre la categoría Estado y gobierno, por ejemplo.

El Estado es el espacio del poder de la sociedad en su conjunto y forman parte del Estado, no sólo el aparato de gobierno, sino también las universidades y las comunidades. Al darse una confusión entre Estado y gobierno, muchas veces las comunidades, pueblos, organizaciones de la llamada sociedad civil, y aun las propias universidades, no comprenden que son parte del Estado. Ver figura $\mathrm{N} 1$.

Frente al tema que aquí se discute, lo importante es comprender que en toda sociedad -y sobre todo en las sociedades de clases- el Estado es el espacio donde se dirimen las relaciones de poder, aquel en que chocan o se confrontan los intereses sociales contra-
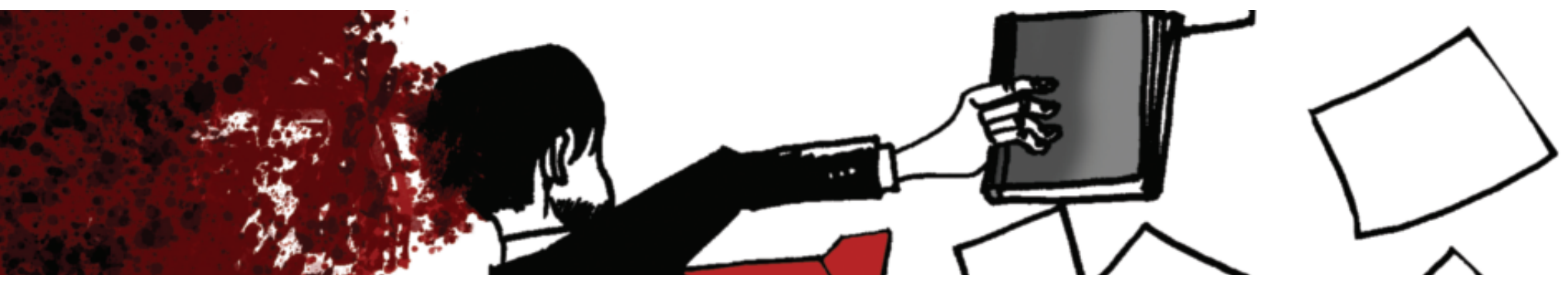
puestos de la sociedad, bajo el paraguas y la lógica de un sistema de reproducción social que, en el caso de nuestra sociedad, es el sistema de acumulación de capital; lógica que no agota pero que marca profundamente la lógica de operación social del gobierno, de las universidades y comunidades.

Para comprender desde una perspectiva emancipadora el papel de cada uno de esos tres elementos en el Estado, frente a las relaciones de poder, es decir para analizar su conjunción como fuerzas de una transformación de dichas relaciones de poder -cuestión que equivale al armado de una conducción público social de la acción concatenada de los tres elementos y la relación entre estos-, es fundamental comprender cuáles son las posibilidades y condiciones especiales de cada uno frente al poder y sus distintos dominios. Grosso modo, el gobierno tiene la capacidad de participar directamente e incidir con fuerza en todos los cinco dominios; las universidades lo hacen principal y más directamente en el dominio académico científico, cultural y sólo indirectamente en los otros; y las comunidades de ciudadanos, de trabajadores, de organizaciones políticas, tienen una incidencia directa, aunque variable sobre el poder económico y de propiedad, pueden incidir poderosamente en el poder político cultural, y algo en lo administrativo (sobre todo en espacios de administración público social), pero menos en las esferas del poder académico científico.

De esa realidad y dependiendo del contexto socio político, se puede desprender un análisis de las relaciones entre la sociedad, el pueblo y las universidades que evite valoraciones equivocadas de la acción posible y distorsiones sobre el papel que le corresponde a cada parte.

Figura No. 1 Estado, universidad pública y comunidad

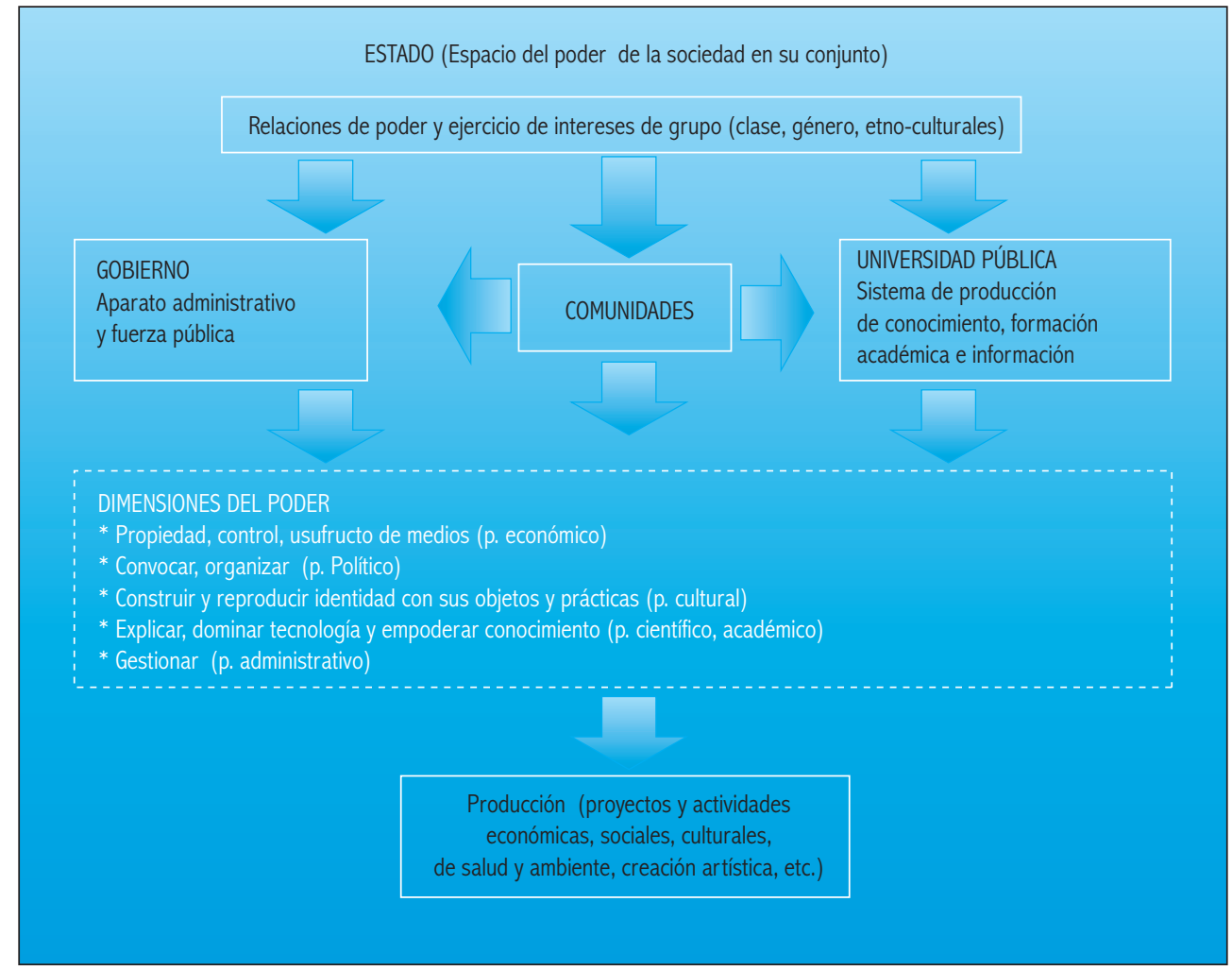

Fuente: Breilh, J. Hacia una universidad soberana, de excelencia y crítica. Quito: Doctorado de salud colectiva, ambiente y sociedad de la Universidad Andina Simón Bolívar - Sede Ecuador, septiembre 2011 
De todas maneras, si bien es evidente que el análisis dependerá del marco interpretativo e ideológico del poder y sus relaciones, esta perspectiva de las relaciones de poder del Estado nos permite construir la opción de combinar las fuerzas especiales de las comunidades, de las universidades y de los espacios democráticos del gobierno para transformar, en sentido profundamente democrático, la sociedad vigente, el régimen de acumulación y el modelo de civilización de la modernidad que se nos ha impuesto y que determinan impactos negativos frente a la justicia social, cultural y ambiental.

Desde los años típicamente neoliberales, y aún ahora que se impulsa un modelo tecnocrático, todavía funcional a la acumulación, el poder de los capitales privados busca incidir sobre las relaciones de poder y las que se dan entre el gobierno, las universidades y las comunidades, creando cortapisas y cerrando espacios para el ejercicio de un quehacer crítico académico.

Como cuando nos vendían como salida auténtica del desarrollo los tratados de libre comercio -TLC-, con sus sofismas, lo primero que tuvimos que hacer las universidades y organizaciones sociales fue comprender las contradicciones y trampas subyacentes y generar respuestas estratégicas. Del mismo modo, ahora que nos venden un proyecto modernizante sin beneficio de inventario, es indispensable asumir con profundidad la comprensión del sistema de contradicciones que la Ley implica frente al juego de poder, más allá de sus supuestas buenas intenciones. En dirección de ese indispensable análisis hemos detectado importantes contraposiciones que expresan el actual debate sobre la universidad y las características que debería tener:

- Conducción público social versus desarrollo funcional burocrático.

- Excelencia académica y crítica versus desarrollo tecnocrático.

- Autonomía universitaria responsable versus subordinación estatista de la educación superior.

- Eficiencia educativa versus manejo tecnocrático gerencial de la educación.

- Equidad educativa versus pérdida de derechos docentes.

- Proyección social de universidades basadas en la colectividad versus instrumentación funcional de los programas al poder y sus empresas.

\section{Líneas estratégicas y categorías para construir el papel de la universidad pública}

Desde una perspectiva crítica de un conocimiento basado en la realidad, el estudio del papel de la universidad pública, es decir de la relación entre la universidad y su sociedad, puede definirse como una incidencia (repercusión científico técnica o estética) que se desdobla en varios aspectos:

1) Impulso de un conocimiento científico crítico o creación artística original, ligados a los procesos claves de la sociedad.

2) Desarrollo de instrumentos técnicos o recursos estéticos para la operación de cambios favorables al bien común.

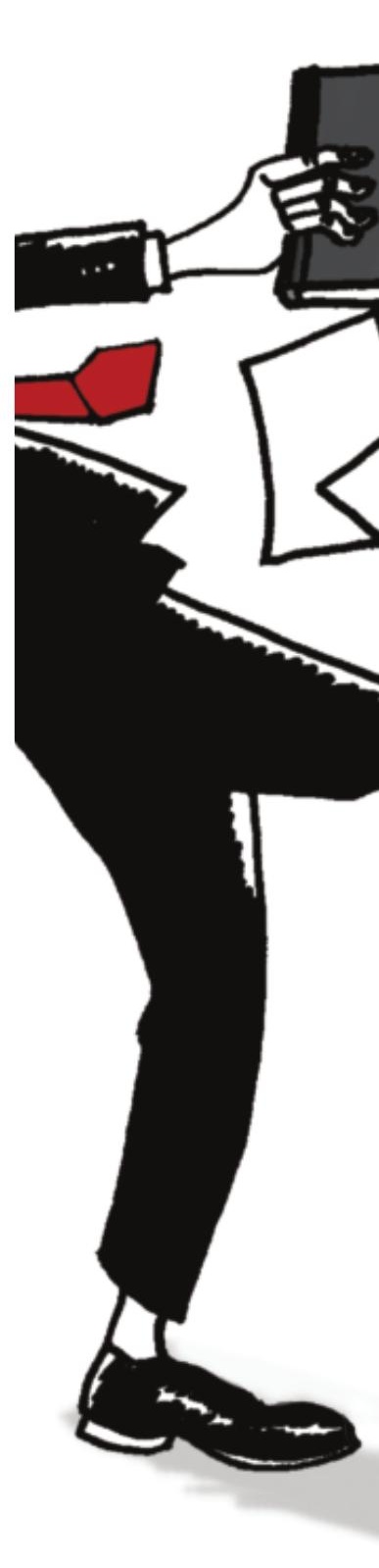


3) Avance de herramientas para el control social, veeduría y rendición de cuentas de los responsables de la gestión, las políticas o el desarrollo artístico (incluidas las propias universidades).

4) Consolidación de mecanismos de construcción intercultural e interdisciplinaria de investigación/creación/incidencia.

5) Contribución, mediante las vías anteriores, al empoderamiento democrático de las colectividades, pueblos y géneros.

Cualquiera de esas vías de incidencia puede direccionarse hacia intereses diversos, o incluso contrapuestos, por lo cual es indispensable pensar que al diseño de los programas universitarios se anticipe un análisis teórico o conceptual sobre los problemas de cada campo disciplinar o estético; y en el caso de las disciplinas científicas, se expliciten los procesos críticos de las mismas. ${ }^{14}$

En segundo lugar, es necesario un análisis político organizativo de los sujetos históricos para los que cobra especial relevancia dicha problemática, así como los aspectos éticos que implica la direccionalidad a la actividad universitaria, vale decir, la medida en que el contenido, intensidad y cobertura de nuestras actividades, ofrece mejores y más eficaces aportaciones al buen vivir.

Y finalmente, las universidades tienen que hacer un balance de las potencialidades, disponibilidades y limitaciones de los recursos técnicos con los que cuentan sus programas.

Los tres elementos descritos se interrelacionan y forman lo que ha sido denominado el triángulo de la política ${ }^{15}$ al que hemos modificado para aplicarlo a la planeación universitaria (ver figura N 2).

\section{Figura No. 2. Triángulo de la planeación estratégica de la investigación / incidencia en la universidad}

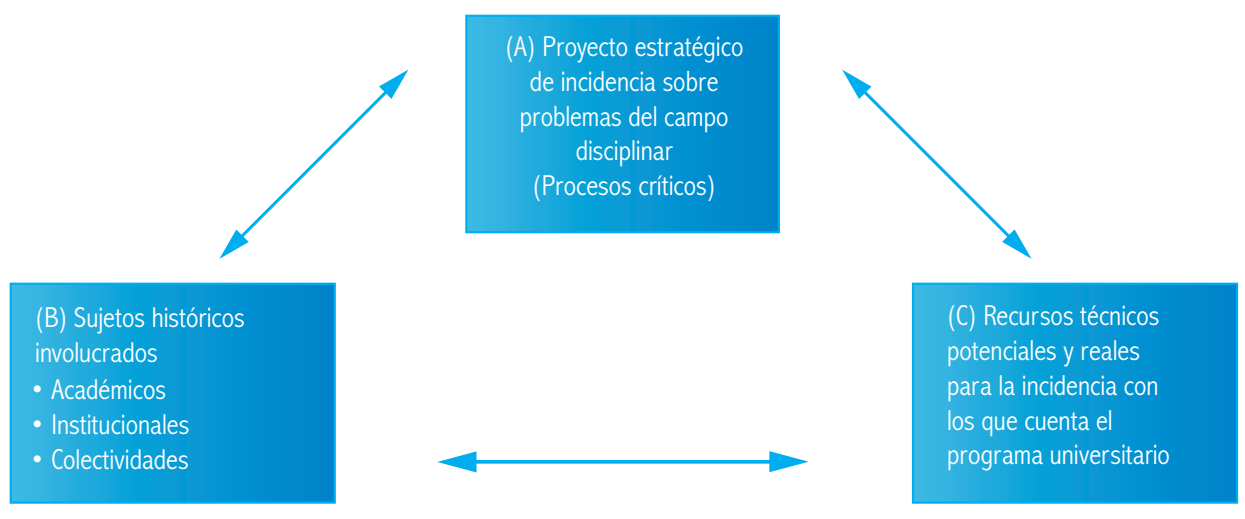

A lo anterior hay que añadir que las universidades que se precian de un alto nivel académico y de aplicar una investigación de excelencia, no pueden desconocer el principio de integralidad que hemos esbozado y abordar mediante una aproximación interdisciplinaria e intercultural el estudio de los hechos en su complejidad y en su doble condición de ser, a la vez, procesos con un movimiento que los determina y resultados de dicho proceso.
14 Proceso crítico es un objeto dinámico de transformación sobre el que incide un quehacer universitario y que forma parte de un eje de investigación /incidencia. En el caso de las ciencias, constituye un objeto que debe ser colectivamente construido, con la participación activa de los sujetos académicos, institucionales y de la colectividad. Dicho proceso se define 0 concreta en la confluencia de una problemática comprendida como estratégica, en un territorio o espacio social en proceso de movilización. En el caso de las artes es un objeto de preocupación estética

15 Carlos Matus, Adiós señor Presidente, Santiago, LOM, 1998.

Modificado por autor de: Carlos Matus: Adiós señor Presidente. Santiago LOM, 1998. 
16 Martha Nolasco. Competencia avaliativa do enfermeiro para o reconhecimento e enfrentamento das necesidades em saúde das familias. Sao Paulo: Tesis de doutoramento nu Doutorado de Enfermagem da Universidade de São Paulo, Marzo 112010

\section{Debate sobre el Modelo de Competencias}

El modelo de competencias ha sido un terreno de debate debido a las distorsiones funcionalistas que puede introducir en la planeación curricular.

Para lo que interesa a los objetivos del presente análisis, se han destacado dos visiones ${ }^{16}$ :

El paradigma de la competencia educativa como adaptación funcional individual (profesionalista, adaptativo, de subjetividad fragmentada); funcionalista, de gerencia eficientista, concentrado con sentido pragmático en los ámbitos resolutivos focales.

El paradigma de la competencia educativa como capacidad de manejo de la complejidad, nivel de conciencia crítica de la realidad y nivel de pensamiento abstracto, donde el trabajo genera sujetos socialmente articulados y dispuestos a mirar los procesos como espacios de transformación integral.

Por consiguiente, un enfoque integral de la planeación educativa no solo se concentra en los elementos profesionales de competencia directa (conocimiento, habilidades y actitudes), autonomía (iniciativa propia), creatividad, compromiso y responsabilidad, sino que incorpora la dimensión colectiva de la competencia económica, cultural, política, rebasando la esfera meramente funcional.

\section{Categorías para la gestión universitaria de la investiga- ción / incidencia}

La planificación de la investigación en la universidad requiere de un conjunto de categorías que explican los distintos niveles de análisis los cuales desglosamos en la figura No 3.

\section{Figura No 3 Categorías para la planeación de la investigación universitaria}

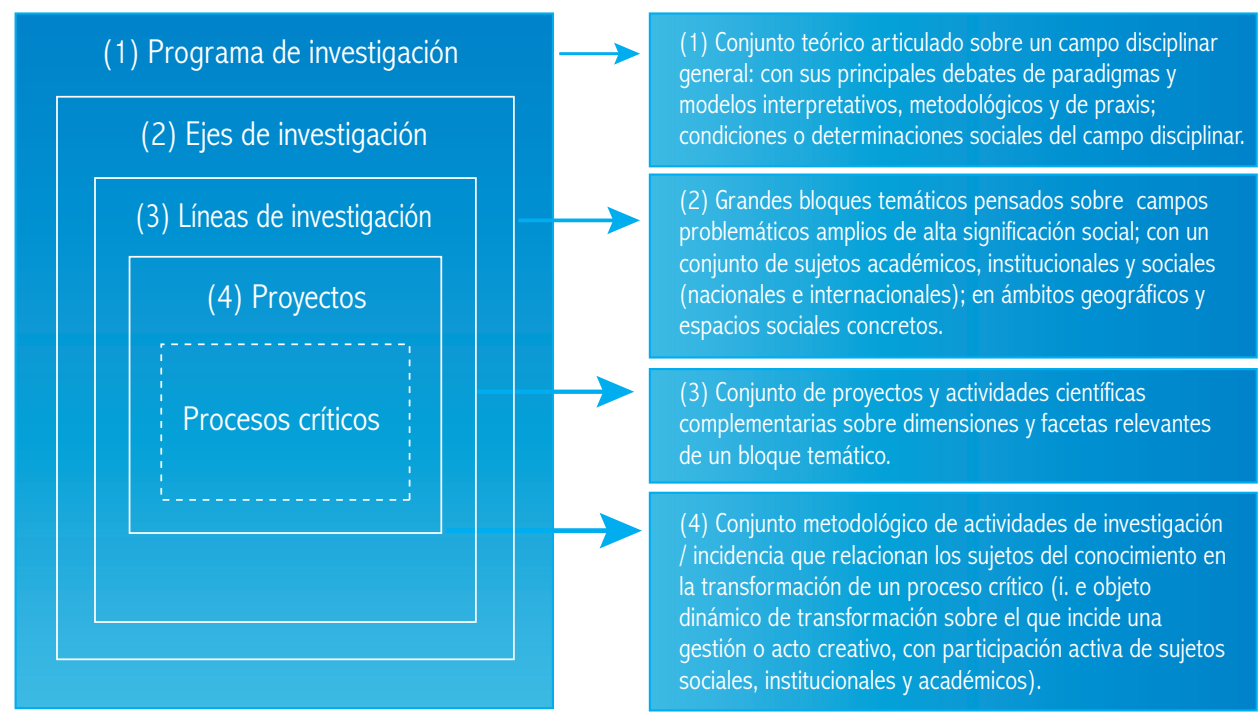

Fuente: Breilh, J. Hacia una universidad soberana, de excelencia y crítica. Cuenca: Conferencia en exposición de proyectos de investigación y extensión de la Facultad de Ciencias Médicas, abril 13 del 2011. 
La coherencia entre estos eslabones del diseño curricular con el proyecto global que se traza un colectivo universitario, y la congruencia entre los distintos niveles (programa, ejes, líneas, proyectos) son vitales para armar un proceso consistente y articulado.

\section{Redefinición crítica del desarrollo (¿La necesidad de sublevar la noción de buen vivir?)}

Un elemento decisivo al definir la direccionalidad de nuestros programas y sus compromisos con la sociedad, constituye la noción o modelo de desarrollo que se aplica u opera como referencia de nuestros planes.

En la actualidad y sobre todo luego del proceso constituyente, el debate sobre el modelo de país despertó un vivo interés por la noción del buen vivir. En el campo de la salud colectiva ese no es un debate reciente, puesto que en el centro de las propuestas alternativas de la llamada medicina social desde los años 70, estuvo ya presente el debate contra las versiones funcionalistas de la llamada "calidad de vida" y la propuesta de la categoría de modos de vivir saludables que se lanzó desde distintos núcleos latinoamericanos.

Ahora bien, es congruente con la meta de esclarecer el compromiso de una universidad, argumentar que es imperativo trabajar por un modelo de desarrollo que permita construir colectivamente el buen vivir; lo cual presupone establecer una noción consistente, real y estratégica del buen vivir.

La nueva Constitución incorpora en ocho secciones los componentes del derecho al buen al buen vivir: agua y alimentación (Sec. 1era); ambiente sano (Sec. 2da); comunicación e información (Sec. 3era); cultura y ciencia (Sec. 4ta); educación (Sec. 5ta); hábitat y vivienda (Sec. 6ta); salud (Sec. 7ma); y trabajo con seguridad social (Sec. 8ava), lo cual abarca un campo importante para la justiciabilidad y la exigibilidad del buen vivir.

A la investigación corresponde profundizar en el buen vivir. Nosotros hemos trabajado dicha noción desde la perspectiva de la protección, promoción y perfeccionamiento de la vida en la Tierra. No sólo la vida humana sino la vida en la naturaleza, para superar un enfoque antropocéntrico del desarrollo, pero sin caer en un biocentrismo ingenuo que desconozca la determinación histórica social de la vida. Como lo hemos explicado en otros trabajos impulsamos un paradigma sociobiocéntrico. ${ }^{17}$

A partir de esa perspectiva se reconoce que los pilares del buen vivir son las que hemos denominado las tres "S" de la vida: una sustentabilidad soberana; una plena solidaridad; y una vida saludable. Por tanto, es necesario que las reflexiones sobre el buen vivir no se sitúen exclusivamente en la dimensión individual y del consumo.
17 Jaime Breilh. Las Tres "S" de la Determinación de la Vida y el Triángulo de la Política. Salvador en "Memorias del Seminario Internacional "Rediscutiendo la Cuestión de la Determinación Social de la Salud" -Edición organizada por el Centro Brasileiro de Estudos de Saúde CEBES, la Universidad Federal de Bahía y la Organización Panamericana de la Salud. Bello Horizonte: Ediciones del CEBES, 2010
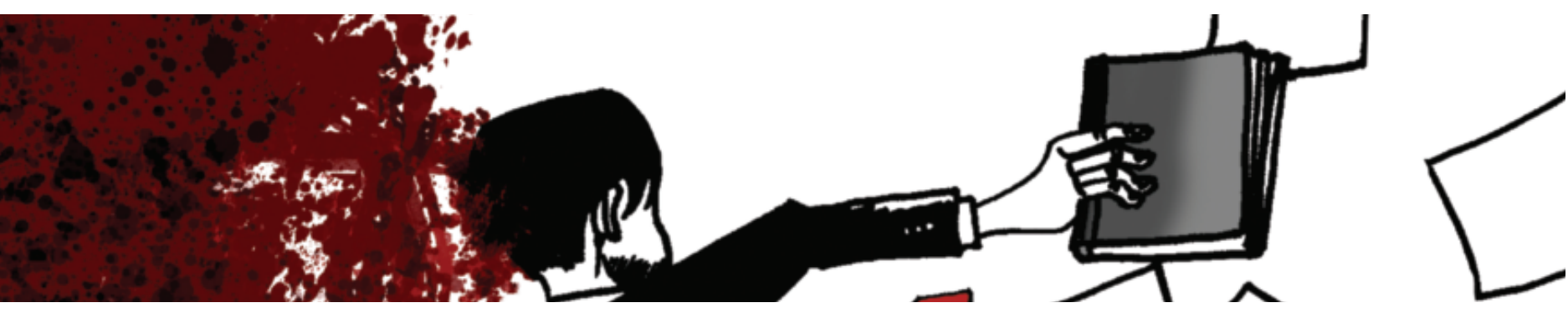
18 Diccionario de la Real Academia Española, en < http://buscon.rae.es/drael/.>
El principio de sustentabilidad requiere que organicemos la producción para generar bienes, alimentos y fertilidad (proteger la biomasa y la biodiversidad), pero para fundamentar o sostener, no cualquier forma de vida sino una vida soberana, plena, digna, feliz y saludable. La sustentabilidad incluye la bioseguridad; control de la base genética del sistema agroalimentario; control de monocultivos de gran escala que deterioran biodiversidad de ecosistemas y estimulan calentamiento; garantía de la calidad sanitaria y nutricional de los alimentos; patentes y la mercantilización de la vida y el conocimiento (cultura, el conocimiento y la tecnología); y una información completa accesible y con participación de los ciudadanos y colectividades.

En segundo lugar el buen vivir requiere de una organización solidaria de la vida, donde la estructura económica productiva se organice alrededor de la preeminencia de la vida y del bien común; donde la distribución ofrezca a todos el acceso de una cuota que haga posible el buen vivir; donde se instaure un sistema de consumo consciente y colectivamente concertado, basado en una construcción consciente y equitativa de la necesidad, sin derroche, ni desperdicio y sin desproporcionar los recursos presentes y futuros; donde todos los pueblos puedan realizar a plenitud su identidad y las potencialidades de su cultura; donde la conducción de la vida colectiva ofrezca a todos la posibilidad de incidir sobre el Estado y el movimiento social; donde todos disfruten del bien protector de la organización social; y donde todos trabajemos juntos por construir razonable y equitativamente un sistema de derechos y responsabilidades frente a la protección de la madre Tierra.

Y finalmente el buen vivir implica también la base de las condiciones saludables y bioseguras. La sociedad saludable implica, sobre la base de las dos "S" o principios anteriores, contar con la posibilidad real de modos de vida que consoliden y perfeccionen, en los diferentes espacios socio culturales, la preeminencia de procesos protectores y soportes, colectivos, familiares e individuales, que posibiliten el predominio de formas fisiológicas y psíquicas que sustenten una buena calidad de vida biológica y psíquica, posibilitando una mayor longevidad, capacidad de asimilación de noxas, potencialidad para la plena actividad física en todas las edades, disfrute del placer y la espiritualidad. Forma parte de una sociedad saludable la que hemos descrito como una naturaleza y vida protegida en lo que antes explicamos como bioseguridad.

A nuestro modo de ver, todas las áreas de una universidad deben enfilar su quehacer hacia la construcción de una vida plena, colocando en el centro las necesidades materiales, culturales y estéticas hacia esa meta, y buscando como las disciplinas y las interdisciplinas contribuyen a consolidar los recursos productivos, administrativos, educativos, artísticos, jurídicos, socio antropológicos, de salud, comunicación, etc., que requiere el proyecto de transformación de una sociedad que, hasta hoy, niega estructural y culturalmente dicho buen vivir.

\section{La utopía: ¿Reforma \\ o revolución?}

Una revolución constituye un giro rápido, una transformación profunda de la naturaleza y características de un espacio socio - político o cultural, de las instituciones económicas, políticas o sociales de una nación". ${ }^{18}$

Pero la visión épica o mítica de las revoluciones como recomienzo absoluto se ha desgastado en la historia concreta de los pueblos. Es material y simbólicamente más potente la idea de la transición histórica como una unidad o síntesis de una sustancia y una forma, donde la dinámica histórica 
puede encerrar un conflicto, una falta de concordancia entre la substancia y la forma, que puede desencadenar un proceso revolucionario. ${ }^{19}$ En los cambios reformistas, las nuevas formas creadas no compiten contra la sustancia o estructura anterior, mientras que en las reformas consistentes los cambios consolidan formas alternativas que compiten y colocan en jaque a la sustancia o estructura anterior.

Desde esa perspectiva, lo que está sucediendo ahora, en el terreno de la Ley como del debate académico, es la preeminencia en la universidad pública ecuatoriana de un reformismo que ni compite contra la educación superior funcional e instrumental a las empresas e instituciones que encarnan el poder empresarial, ni peor enfilan seriamente a construir las dimensiones emancipadoras del buen vivir, protegiendo la autonomía relativa de la ciencia para que no se confundan los espacios universitarios con partidos políticos ni con ONGs.

Es indispensable armarnos de sabiduría y buena organización para emprender una lucha por la reforma universitaria que necesitamos desencadenar, para poner en marcha una educación pública de excelencia, pero articulada orgánicamente al estudio y transformación de los procesos críticos, de una realidad cuyos rasgos esenciales son: la injusticia socio económica; la inequidad cultural; y la injustica ambiental.

El camino se nos presenta empinado y lleno de obstáculos pero mientras existan espacios democráticos en las universidades públicas, de mentalidad innovadora y de vínculos auténticos con nuestro pueblo, podremos combinar altos niveles de calidad académica, tanto en los campos clínicos quirúrgicos como en la salud colectiva, con un conjunto de programas de extensión universitaria, innovadores y auténticamente situados junto a su pueblo, que nos permitan mostrar al Ecuador lo que puede lograrse con una conciencia social clara, con honestidad intelectual y con una férrea voluntad de trabajo.
19 Bolivar Echeverría, "La izquierda: reforma y revolución", en Utopías 